\title{
Reseña. Pablo Jarne Muñoz, Economía colaborativa y plataformas digitales. Madrid, España: Reus, 2019. ISBN: 978-84-290-2137-0
}

La economía colaborativa es un fenómeno relativamente nuevo que se está expandiendo, a nivel global, a una velocidad de vértigo. Su origen obedece, en gran parte, a la generalización de las nuevas tecnologías, pero, sobre todo, a la red. Ambos permiten el encuentro entre usuarios con la finalidad de intercambiar bienes y servicios. Esencialmente son relaciones humanas que, hasta hace relativamente poco, se planteaban únicamente en el seno de comunidades de familiares, vecinos o, incluso, amigos. De hecho, en muchas ocasiones, no tenían fines de lucro, ya que se trataba de actividades tan mundanas como prestarse la casa, invitar a un familiar unos días, o permitir a un amigo usar la bicicleta o patinete.

Todo ello cambió radicalmente con la implantación y consolidación de las plataformas digitales. De alguna manera, su llegada supone una alteración sin precedentes de lo que, hasta la fecha, había imperado. Existe una amplísima variedad de plataformas digitales que hacen uso de la economía colaborativa en numerosos ámbitos de la vida cotidiana. Nos referimos, entre otros, al transporte, la entrega de comida, el alojamiento y un largo etcétera.

Las plataformas que operan dentro de lo que podría considerarse como economía colaborativa están surgiendo con base en las modificaciones fundamentales en los hábitos de consumo (así, por ejemplo, Couchsurfing, Airbnb, Uber, Spotify y Waze). Estas últimas han derribado a sectores bien posicionados y con cierto arraigo, con su denominada disrupción creativa en un breve espacio de tiempo. Están suscitando modificaciones en todas las áreas cotidianas y, a buen seguro, traerán profundos cambios a nuestro entorno empresarial.

Resulta necesario adoptar un modelo de regulación que favorezca estas nuevas modalidades sin permitir abusos del consumidor ni, mucho menos, de los trabajadores de estas compañías. En sentido estricto, no se trata de meras intermediarias. Van más allá. En puridad constituyen plataformas que limitan aspectos que, hasta fechas recientes, eran determinantes en la cadena de valor y que suprimen intermediarios. En efecto, no son empresas de índole tecnológica que ponen en marcha una aplicación informática para el 
intercambio de bienes y/o servicios entre particulares. La problemática que, en este orden de cuestiones, se suscita es ciertamente amplia y, a su vez, compleja.

A todo ello responde la obra que es objeto de reseña. El prólogo, a cargo del Dr. Monge Gil, anticipa las bondades de su contenido. Antes de entrar de manera somera en las diversas partes en las que se estructura la monografía, cabe manifestar que conjuga la sencillez y el rigor más absoluto. Cuenta con un total de cuatro capítulos.

El primero de ellos, que tiene por rúbrica "La Economía colaborativa. Origen y presupuestos", estudia esta cuestión como fenómeno contemporáneo, analizando las causas de su desarrollo y caracteres inherentes. Posteriormente, aborda sus efectos en los mercados. Así, en este sentido, trata la incidencia tanto del Derecho de defensa de la competencia como de la competencia desleal. Como Jarne Muñoz apunta, de forma acertada, una de las mayores dificultades a las que se ha enfrentado la economía colaborativa está relacionada con la ausencia de normativa propia aplicable a este movimiento. Muy conveniente resulta la apreciación relativa a la autorregulación del sector. En todo caso, quizás podría ser beneficioso para todos los sectores (consumidores, sociedad y sector público) incentivar una autorregulación regulada.

Seguidamente, en el segundo capítulo se analizan las plataformas en línea como herramientas en virtud de las cuales tiene lugar la economía colaborativa. Naturalmente, es un presupuesto para que puedan plantearse las relaciones en estos modelos de negocio.

Por su parte, el capítulo tercero versa sobre los prestadores del servicio subyacente y los consumidores. Debe prestarse especial atención a la posición que se atribuya al consumidor $\mathrm{y}$, por ende, los deberes que le sean de aplicación. El autor indica que el estatuto que haya de atribuirse a los prestadores de servicios colaborativos es una cuestión delicada, por la disparidad de perfiles que operan en una misma plataforma.

El capítulo final se refiere a las particularidades sectoriales que se suscitan en el alojamiento o el transporte. De hecho, las plataformas que han operado en dichos sectores han incidido, en gran medida, sobre el régimen jurídico aplicable a la economía colaborativa. Son ámbitos fuertemente relacionados con el sector servicios, que, sin embargo, no guardan una aparente conexión entre sí. El éxito que alojamientos vacacionales, como el modelo de Airbnb, han protagonizado, como señala el autor, contrasta abiertamente con las dudas que las viviendas de uso turístico generan a nivel normativo. Y es que a la diversidad normativa que deriva del Estado de las autonomías se suma la existencia de cuestiones de muy difícil reglamentación, como la fijación de 
una limitación temporal a que ha de someterse esta modalidad de alojamiento o las dudas en materia de responsabilidad y aseguramiento.

Como el autor plantea, son muy numerosos los sectores que han visto alterada su existencia, habida cuenta de la irrupción de las plataformas de la economía colaborativa. El movimiento asociado a este fenómeno supone una importante transformación cultural y económica de las sociedades. Se pasa de una migración de un consumo fuertemente individualizado a nuevos modelos fomentados por las redes sociales y aplicaciones tecnológicas que le sirven de herramienta para poder operar (sin perjuicio de que muchas de ellas son, asimismo, accesibles por sitio web).

Estamos siendo protagonistas de una verdadera modificación de los pilares decimonónicos sobre los que hemos venido operando hasta ahora. En efecto, la propiedad de los bienes pasa a un segundo plano, y lo que se potencia es el acceso a estos y lo que nos proporcionan. Hoy en día no se paga por comprar productos o servicios, se paga por usarlos.

Dr. David López Jiménez ORCID:0000-0002-7013-9556

EAE Business School, España Correo:dlopez@eae.es 